\title{
Hydrochemical Characteristics and Irrigation Water Evaluation of Suburban River: A Case Study of Suzhou City, Anhui Province, China
}

\author{
Manli Lin*(**), Hao Yu** and Weihua Peng*(***)† \\ *School of Resources and Civil Engineering, Suzhou University, Suzhou 234000, PR China \\ **National Engineering Research Center of Coal Mine Water Hazard Controlling, Suzhou University, Suzhou 234000, \\ PR China \\ ***Key Laboratory of Mine Water Resource Utilization of Anhui Higher Education Institutes, Suzhou University, \\ Suzhou 234000, PR China \\ $†$ Corresponding author: Weihua Peng; pengweihuapwh@126.com
}

Nat. Env. \& Poll. Tech. Website: www.neptjournal.com

Received: 20-02-2021

Revised: 25-03-2021

Accepted: 03-04-2021

\section{Key Words:}

Hydrochemical characteristics Principal component analysis Agricultural non-point source pollution

Xinbian river

\begin{abstract}
To study the evolution of hydrochemical characteristics and the quality of irrigation water from a suburban river, a total of 54 water samples were collected from Xinbian River in Suzhou City (Anhui Province, China) from December 2019 to May 2020. Piper diagrams, Gibbs diagrams, and multivariate statistical analysis were used to analyze the hydrochemical characteristics and main ion sources. Research results showed that the content of main ions increased continuously from December 2019 to May 2020, among which $\mathrm{SO}_{4}{ }^{2-}$ and $\mathrm{F}^{-}$exceeded China's surface water quality standards in April and May. The main hydrochemical type was $\mathrm{Na}_{-} \mathrm{SO}_{4}$, accounting for $77.77 \%$, of water samples with the main ion components found to be related to rock weathering. Correlation analysis and principal component analysis showed that agricultural non-point source pollution was the main factor affecting the water quality of the Xinbian River. Overall, the evaluation index of irrigation water shows that Xinbian River was suitable for irrigation utilization, although the effects of magnesium damage should be prevented.
\end{abstract}

\section{INTRODUCTION}

Urban rivers play an important role in urban development, supplying water for cities and maintaining urban ecological balance (Hu et al. 2020). However, with the rapid development of urbanization and industrialization in recent years, the concentration of pollutants in urban watersheds is continually increasing (Valappil et al. 2020, Yu et al. 2020a), especially in urban fringe areas where there is no obvious boundary between urban and rural environments and where different ecosystems merge and compete. For example, a large amount of agricultural land has been converted for use as urban construction land and industrial land (Tang et al. 2020). The disposal of pesticides, chemical fertilizers, wastewater, waste gas, and solid waste produced industrially has a direct effect on the chemical characteristics and water quality of rivers in urban fringe areas (Jiang et al. 2020, Yu et al. 2020a).

The hydrochemical characteristics of surface water are mainly affected by water-rock interactions, evaporation concentration, and human activities (Wang et al. 2019a). Through the analysis of river water chemistry, the geochemical source of river ions can be clarified (Xia et al. 2019). Based on this, many previous studies have assessed river water chemistry characteristics and evaluated potential applications. Valappil et al. (2020) assessed surface water from the Limbang River Basin in Kalimantan, using Piper diagrams, Gibbs diagrams, and multivariate statistical analysis, showing that atmospheric rainfall and rock weathering were the main factors affecting the chemical characteristics of surface water in the study area. Hu et al. (2020) compared differences in the conventional components and heavy metal content of wetland water under various land-use conditions, finding that $\mathrm{Cl}$ - the content was mainly related to pesticides and chemical fertilizers used in agricultural production, while heavy metal element concentrations were affected by both natural and human sources. Wang et al. (2019b) studied the water chemistry characteristics, control factors, and water quality of the Nu River, finding that rock weathering was the main source of ions and that most Nu River water samples were suitable for irrigation use.

Xinbian River is a large-scale artificial river, which plays an important role in both agricultural development and maintaining the aquatic ecological balance of Suzhou city. The Xinbian River was continuously monitored for six months in this study, according to the features of the local farming cycle. 
Samples were taken to examine the evolution of chemical characteristics in Xinbian River water as well as the quality of irrigation water generated, providing a scientific basis for river aquatic environment protection in urban fringe areas.

\section{MATERIALS AND METHODS}

\section{Study Area}

Suzhou is located in the northernmost part of Anhui Province (Fig. 1a), in the northeast of Huaibei plain, covering a total area of $9787 \mathrm{~km}^{2}$ (Li et al. 2020.). The city's permanent resiy dent population is 5.68 million and water resources in the city are relatively scarce, reaching a total volume of about 3.48 billion $\mathrm{m}^{-3}$. Xinbian River is located in the northern suburbs of Suzhou City (Fig. 1b), with a total length of $127.2 \mathrm{~km}$ and a drainage area of $6562 \mathrm{~km}^{2}$. The annual average discharge and annual average water level elevations are 3.52-72.10 $\mathrm{m}^{3} . \mathrm{s}^{-1}$ and $14.73-26.56 \mathrm{~m}$, respectively. The climate includes very cold and long-lasting winters, with hot summers and long rainy seasons, during which time the precipitation level is concentrated and high. Since its establishment, the Xinbian River has exhibited multiple benefits such as flood control, drainage, and irrigation, contributing significantly to agricultural production and both urban and rural economic development.

\section{Sampling and Testing}

From December 2019 to May 2020, the Suzhou Urban Section of the Xinbian River was monitored in six consecutive monthly sampling campaigns. Nine monitoring points (Fig. 1c) were sampled each month and 54 water samples were collected totally. The sampling specifications were based on the technical specification for surface water and sewage monitoring (HJ/T 91-2002) (SEPA 2002). The water samples were sampled below $0.5 \mathrm{~m}$ of the water surface using a selfmade surface water sampler. Conductivity (EC), pH, and total dissolved solids (TDS) were measured on-site using portable devices. All samples were sent to the laboratory within 24 $\mathrm{h}$ and stored at $4^{\circ} \mathrm{C}$.

After water samples were filtered through $0.45 \mu \mathrm{m}$ filter membranes, the content of $\mathrm{Na}^{+}, \mathrm{K}^{+}, \mathrm{Ca}^{2+}, \mathrm{Mg}^{2+}, \mathrm{Cl}^{-}$, $\mathrm{F}^{-}$, and $\mathrm{SO}_{4}{ }^{2-}$ in water was tested by ion chromatography (ICS-600-900, Diane Co., US). The content of $\mathrm{CO}_{3}{ }^{2-}$ and $\mathrm{HCO}_{3}{ }^{-}$was measured by the acid-base titration method, and the milligram equivalent balance of cations and anions was controlled within $5 \%$.

\section{Data analysis}

Xinbian River is mostly within an agricultural irrigation area and therefore, water quality is very important for the growth
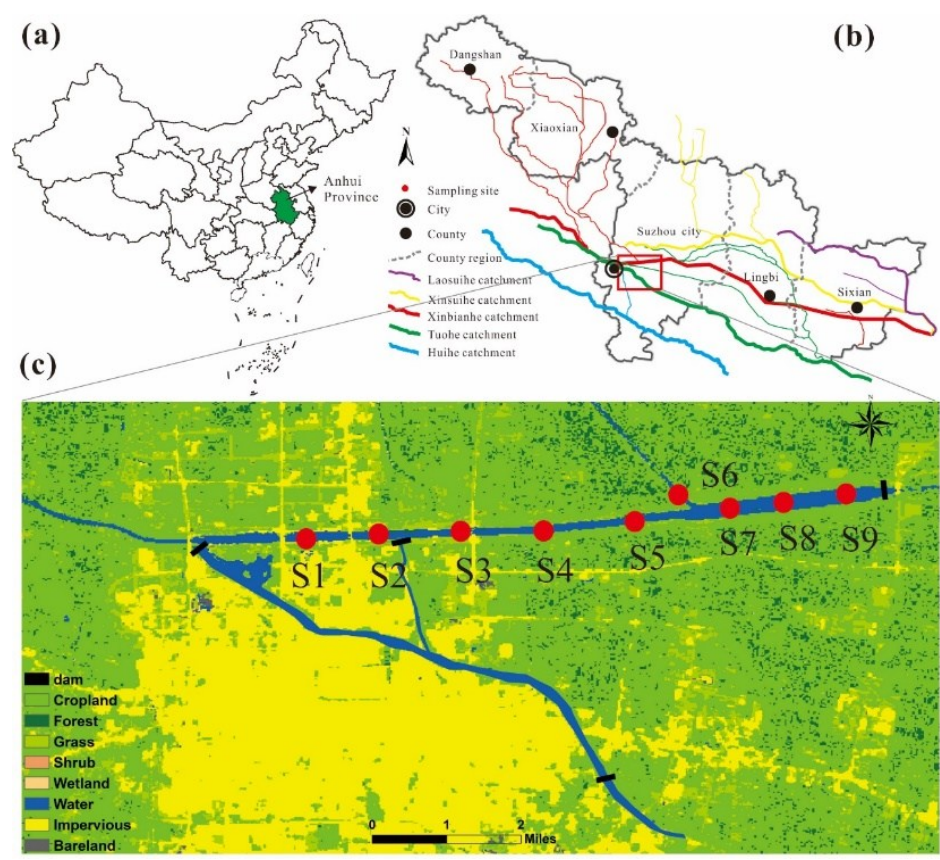

(Source: (a) from Chen et al. 2020; (c) from Jiang et al. 2020)

Fig. 1: Study area and sampling locations. 
of crops. Excessive sodium levels in the water will result in soil permeability being reduced (Bob et al. 2016), which adversely affects crop quality and yield (Guan et al. 2018). Therefore, the irrigation water quality model was used to evaluate the water quality in the present study. The selected indicators were sodium absorption ratio (SAR), residual sodium carbonate (RSC), sodium percentage (Na\%), permeability index (PI), magnesium hazard (MH), and Kelley's ratio (KR). These indicators were calculated according to Eq. (1)-(7) as follows:

$$
\begin{aligned}
& \mathrm{Na} \%=\frac{\left(\mathrm{Na}^{+}+\mathrm{K}^{+}\right) \times 100}{\mathrm{Ca}^{2+}+\mathrm{Mg}^{2+}+\mathrm{Na} a^{+}+\mathrm{K}^{+}} \\
& S A R=\frac{N a^{+}}{\sqrt{\left(C a^{2+}+M g^{2+}\right) / 2}} \\
& M H=\frac{M g^{2+}}{C a^{2+}+M g^{2+}} \times 100 \\
& P I=\frac{\mathrm{Na}^{+}+\sqrt{\mathrm{HCO}_{3}}{ }^{-}}{\mathrm{Ca}^{2+}+\mathrm{Mg}^{2+}+\mathrm{Na}^{+}+\mathrm{K}^{+}} \\
& K R=\frac{N a^{+}}{C a^{2+}+M g^{2+}} \\
& P S=C l^{-}+\frac{1}{2} S_{4}^{2-}
\end{aligned}
$$$$
R S C=\left(\mathrm{CO}_{3}{ }^{2-}+\mathrm{HCO}_{3}{ }^{-}\right)-\left(\mathrm{Ca}^{2+}+\mathrm{Mg}^{2+}\right)
$$

\section{RESULTS AND DISCUSSION}

\section{Ion Content Characteristics}

The results of statistical analysis of the water chemical parameters for the Xinbian River from December 2019 to May 2020 are shown in Table 1. The $\mathrm{pH}$ value (Fig. 2a) of the Xinbian River ranged from 7.75 to 9.50 , with an average of 8.57 which was classified as weakly alkaline water. The TDS value ranged between 445.67 and $732.00 \mathrm{mg} . \mathrm{L}^{-1}$, with an average of $633.49 \mathrm{mg} . \mathrm{L}^{-1}$, while the TDS content exhibited an increasing trend overall (Fig. 2b).

The TDS content of water is related to the total ion content, as shown by the hydrochemical parameters for the Xinbian River in Fig. 2b. Agricultural activities, evaporation, and human activities may increase the TDS content of river water. The $\mathrm{Ca}^{2+}$ content ranged from $28.34 \mathrm{mg} . \mathrm{L}^{-1}$ to 69.74 mg. $\mathrm{L}^{-1}$, with an average value of 48.74 mg. $\mathrm{L}^{-1}$ (Fig. 2c). The trend in variation of $\mathrm{Ca}^{2+}$ exhibited an initial increase, followed by a decrease. The $\mathrm{Mg}^{2+}$ content ranged from 35.24 $\mathrm{mg} . \mathrm{L}^{-1}$ to $62.31 \mathrm{mg} . \mathrm{L}^{-1}$, with an average of $48.49 \mathrm{mg} . \mathrm{L}^{-1}$, exhibiting an overall increasing trend (Fig. 2d). The $\mathrm{Na}^{+}$and $\mathrm{K}^{+}$concentrations ranged from $128 \mathrm{mg} . \mathrm{L}^{-1}$ to $269 \mathrm{mg} . \mathrm{L}^{-1}$ and from $7.34 \mathrm{mg} . \mathrm{L}^{-1}$ to $12.66 \mathrm{mg} . \mathrm{L}^{-1}$, with averages of $157.21 \mathrm{mg} . \mathrm{L}^{-1}$ and $10.11 \mathrm{mg} . \mathrm{L}^{-1}$, respectively (Fig. 2e and Fig. 2f). The $\mathrm{HCO}_{3}{ }^{-}$concentration ranged between 276.51 mg. $\mathrm{L}^{-1}$ and $138.96 \mathrm{mg} . \mathrm{L}^{-1}$, with an average of $232.86 \mathrm{mg} . \mathrm{L}^{-}$ 1 , exhibiting a gradually decreasing trend overall (Fig. $2 \mathrm{~g}$ ). The $\mathrm{SO}_{4}{ }^{2-}$ content ranged from $178.34 \mathrm{mg} . \mathrm{L}^{-1}$ to 406.03 $\mathrm{mg} . \mathrm{L}^{-1}$, with an average value of $270.62 \mathrm{mg} . \mathrm{L}^{-1}$, exhibiting a rapidly increasing trend. From February to May 2020, the content of $\mathrm{SO}_{4}{ }^{2-}$ in water samples regularly exceeded the standard of $250 \mathrm{mg} . \mathrm{L}^{-1}$ (Fig. 2h), as defined by the China surface water quality standard (GB 3838-2002) (except for some samples in March 2020). The change in $\mathrm{Cl}^{-}$concentration was consistent with that of $\mathrm{SO}_{4}{ }^{2-}$ (Fig. 2i), showing an increasing trend. $\mathrm{Cl}^{-}$and $\mathrm{SO}_{4}{ }^{2-}$ are usually associated with strong evaporation, agricultural non-point source pollution, and sewage discharge. $\mathrm{F}^{-}$concentrations increased between December 2019 and May 2020 (Fig. 2j).

\section{Sources of Major Ions and Hydrogeochemical Evolution}

Hydrochemical characteristics: Piper three-line diagrams are commonly used to examine the chemical composition features of water and can intuitively reflect the composition and concentration of anions and cations in the water body (Chen et al. 2019, 2020). Fig. 3 shows the hydrochemical characteristics of the Xinbian River from December 2019 to May 2020, exhibiting three types of water chemistry characteristics: $\mathrm{Na}-\mathrm{HCO}_{3}, \mathrm{Na}-\mathrm{Cl}$, and $\mathrm{Na}-\mathrm{SO}_{4}$, among which the $\mathrm{Na}-\mathrm{SO}_{4}$ type was the dominant type.

From the distribution of cations in the lower-left corner of Fig. 3, it can be seen that the proportion of $\mathrm{Na}^{+}+\mathrm{K}^{+}$in cations in the Xinbian River was higher than other cations, indicating Xinbian River water was Na type. According to the distribution of anions in the lower right corner of Fig. 3 and the trend of change of anions in Fig. 2, $\mathrm{SO}_{4}{ }^{2-}$ was the dominant anion in water samples except for December 2019 (dominated by $\mathrm{HCO}_{3}{ }^{-}$) and January 2020 (mixed type). It can be concluded that the chemical characteristics type of the Xinbian River gradually changed from $\mathrm{Na}-\mathrm{HCO}_{3}$ to $\mathrm{Na}-\mathrm{SO}_{4}$, which may be related to agricultural activities in the surrounding area. Sulfate is the main component of compound fertilizer, providing $\mathrm{SO}_{4}{ }^{2-}$ for crop growth. Therefore, the high concentration of $\mathrm{SO}_{4}{ }^{2-}$ may be related to the use of chemical fertilizer in agricultural production (Hu et al. 2020).

\section{Mechanistic Analysis of Water-rock Interactions}

The Gibbs map was established based on surface waters worldwide. In the Gibbs diagram, rock weathering, evaporative crystallization, and atmospheric precipitation are con- 

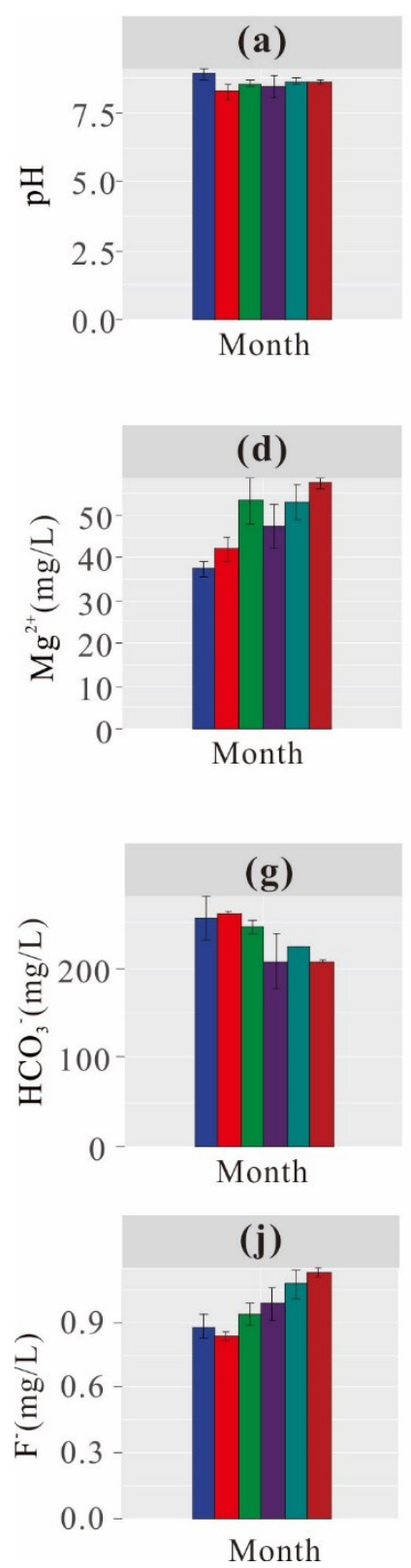
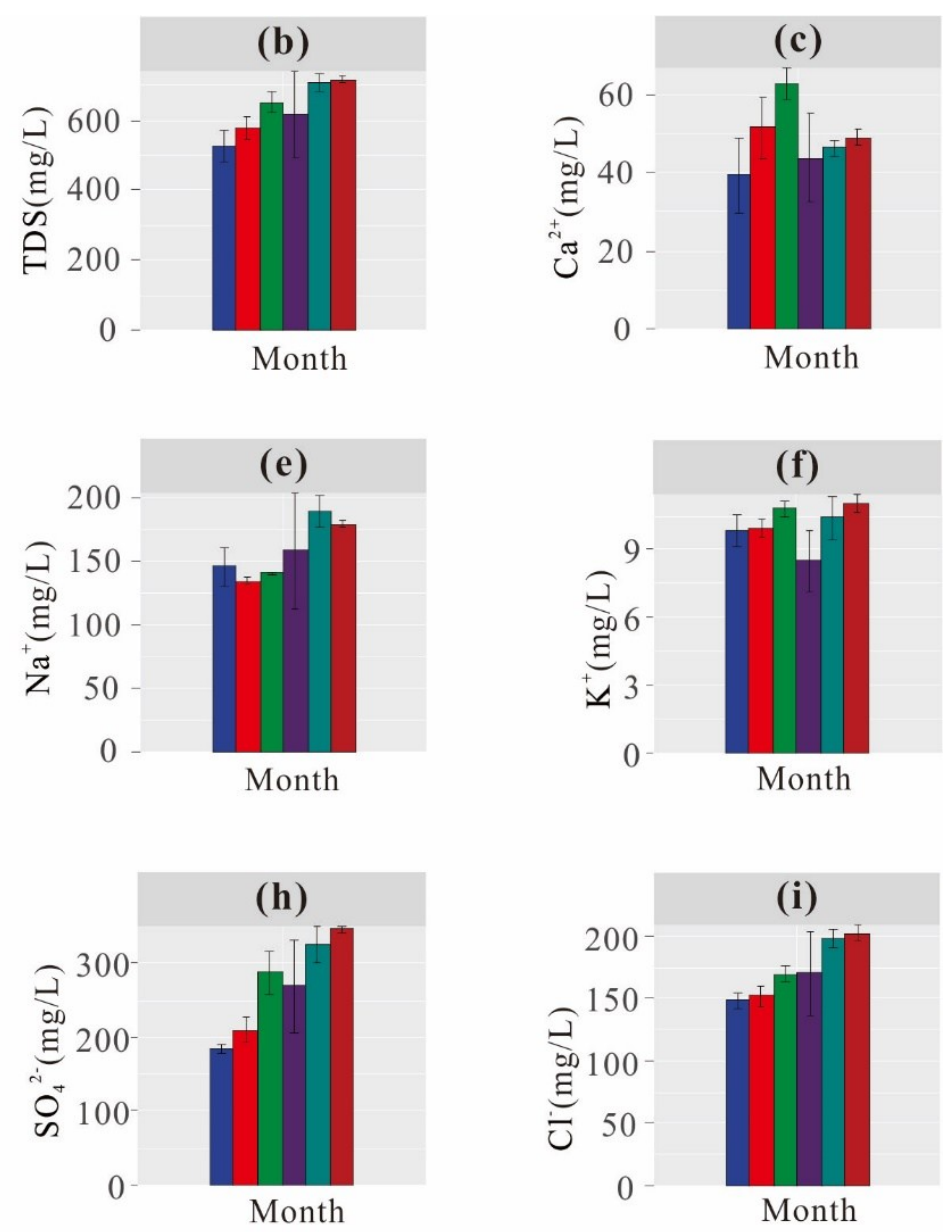

2019-December 2020-January 2020-February 2020-March 2020-April 2020-May

Fig. 2: Variation in average hydrochemical parameters in Xinbian River from December 2019 to May 2020.

sidered to be the three main factors controlling the chemical composition of natural water. Samples dominated by rock weathering are located in the middle left area of the Gibbs diagram, while samples dominated by evaporation crystallization are located in the upper right corner, and samples dominated by atmospheric precipitation are located in the lower right corner. It can be seen from Fig. 4a that water samf ples from the Xinbian River were mostly located in the rock weathering control region of the Gibbs diagram, indicating that the ions in the Xinbian River were mainly from rock weathering. In addition, it can be seen from Fig. $4 \mathrm{~b}$ that some samples were located in the middle left region, indicating that the ions in the Xinbian River not only originated from rock weathering, evaporative crystallization, and atmospheric precipitation, but also human activities, ion exchange, and other factors (Wang et al. 2019a).

Based on the study of solutes in major rivers worldwide, Gaillardet et al. (1999) found that the influence of silicate 


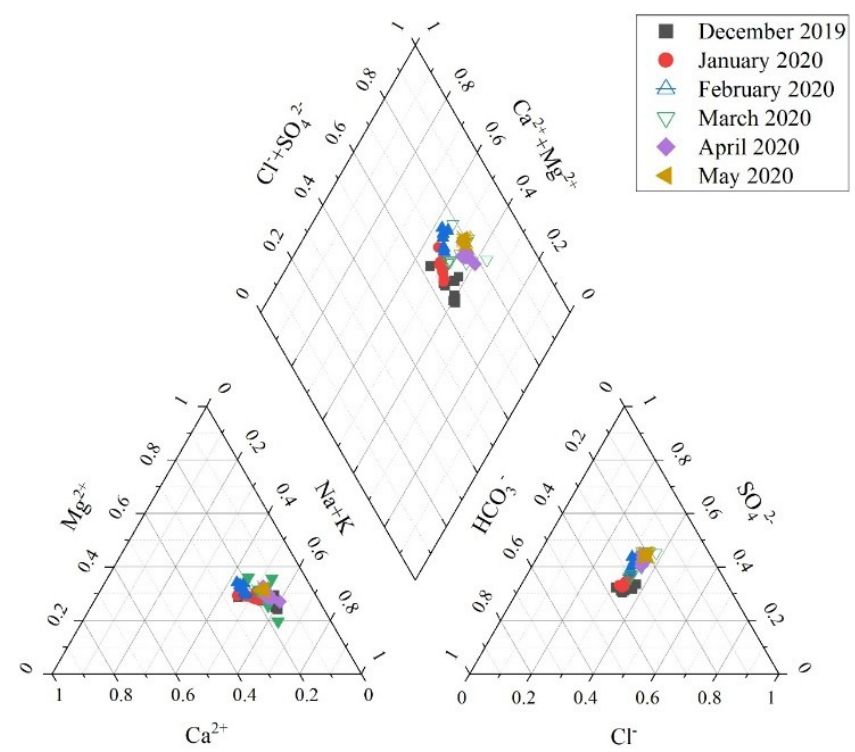

Fig. 3: Piper diagram of the hydrochemical characteristics of the Xinbian River throughout the sampling period from December 2019 to May 2020.

weathering, evaporite, and carbonate dissolution on the water can be determined by the ion molar ratio. As shown in Fig. 5, the Xinbian River water samples were mainly located near the silicate region, while some water samples were located in the evaporite region, which indicates that the solutes in the Xinbian River were mainly affected by silicate weathering, while the impact of evaporite was relatively small.

Table 1: Descriptive statistics of hydrochemical parameters.

\begin{tabular}{|llllllllllll|}
\hline Month & Parameter & $\mathrm{pH}$ & $\mathrm{TDS}$ & $\mathrm{Ca}^{2+}$ & $\mathrm{Mg}^{2+}$ & $\mathrm{Na}^{+}$ & $\mathrm{K}^{+}$ & $\mathrm{HCO}_{3}^{-}$ & $\mathrm{SO}_{4}{ }^{2-}$ & $\mathrm{Cl}^{-}$ & $\mathrm{F}^{-}$ \\
\hline \multirow{2}{*}{ December } & Max & 9.22 & 594.67 & 61.10 & 40.87 & 163.85 & 11.02 & 276.51 & 192.24 & 155.03 & 0.95 \\
& Min & 8.49 & 445.67 & 28.34 & 35.24 & 119.79 & 8.71 & 200.63 & 178.34 & 132.90 & 0.78 \\
& mean & 8.90 & 527.04 & 39.20 & 37.37 & 145.37 & 9.84 & 255.53 & 184.95 & 148.64 & 0.88 \\
January & Max & 8.68 & 640.00 & 69.35 & 47.94 & 137.70 & 11.04 & 261.93 & 245.78 & 166.40 & 0.88 \\
2020 & Min & 7.75 & 538.33 & 44.23 & 38.89 & 128.71 & 9.60 & 257.36 & 193.52 & 137.15 & 0.81 \\
& mean & 8.25 & 577.22 & 51.57 & 42.15 & 133.96 & 9.96 & 260.69 & 210.18 & 151.89 & 0.84 \\
February & Max & 8.72 & 704.00 & 69.74 & 61.57 & 140.83 & 11.47 & 249.19 & 332.43 & 177.27 & 1.04 \\
2020 & Min & 8.30 & 612.00 & 58.62 & 46.82 & 138.73 & 10.35 & 225.40 & 253.22 & 160.04 & 0.87 \\
& mean & 8.53 & 650.96 & 62.71 & 53.53 & 139.63 & 10.82 & 245.50 & 287.66 & 169.02 & 0.94 \\
March & Max & 9.50 & 923.00 & 65.37 & 60.39 & 269.99 & 11.61 & 228.75 & 406.03 & 250.22 & 1.12 \\
2020 & Min & 8.14 & 540.50 & 25.08 & 43.52 & 132.13 & 7.34 & 138.96 & 215.10 & 147.18 & 0.86 \\
& mean & 8.45 & 619.72 & 43.83 & 47.19 & 157.83 & 8.51 & 206.90 & 269.38 & 169.87 & 0.98 \\
April & Max & 8.76 & 741.00 & 48.67 & 62.31 & 213.89 & 12.66 & 224.79 & 363.82 & 212.58 & 1.21 \\
2020 & Min & 8.51 & 669.00 & 41.06 & 49.60 & 173.35 & 9.59 & 221.67 & 288.05 & 186.55 & 1.02 \\
& mean & 8.64 & 709.94 & 46.27 & 53.00 & 187.89 & 10.41 & 223.38 & 325.86 & 197.59 & 1.08 \\
May & Max & 8.73 & 732.00 & 53.61 & 59.48 & 182.72 & 11.56 & 206.36 & 356.89 & 210.47 & 1.16 \\
2020 & Min & 8.50 & 704.50 & 47.42 & 55.56 & 173.54 & 10.51 & 203.92 & 336.79 & 193.23 & 1.09 \\
& mean & 8.62 & 716.06 & 48.85 & 57.69 & 178.58 & 11.10 & 205.17 & 345.70 & 201.83 & 1.13 \\
\hline
\end{tabular}



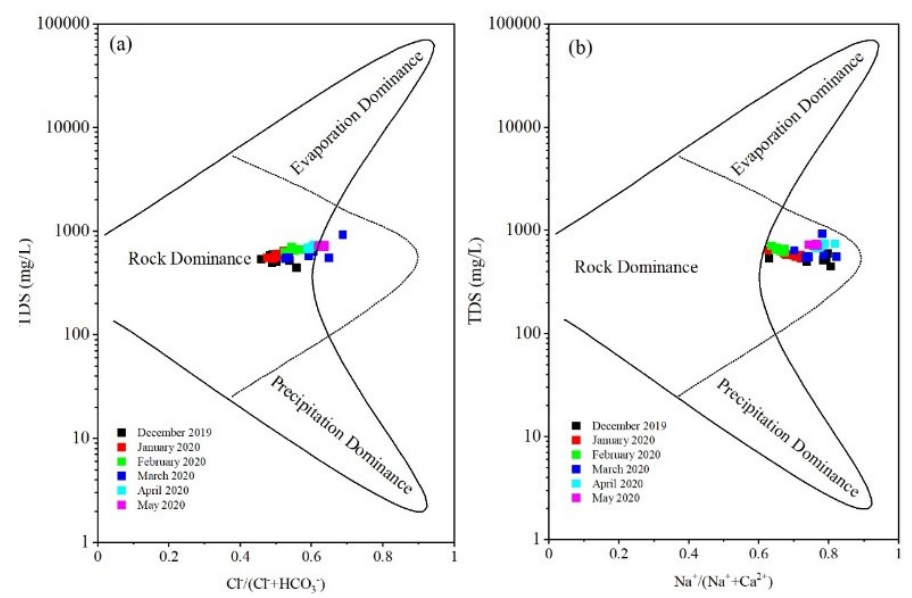

Fig. 4: Gibbs diagrams showing the influence of factors controlling the chemical composition of the Xinbian River throughout the sampling period from December 2019 to May 2020 (a: TDS versus $\mathrm{Na}^{+} /\left(\mathrm{Na}^{+}+\mathrm{Ca}^{2+}\right)$; b TDS versus $\mathrm{Cl}^{-} /\left(\mathrm{Cl}^{-}+\mathrm{HCO}_{3}^{-}\right)$).
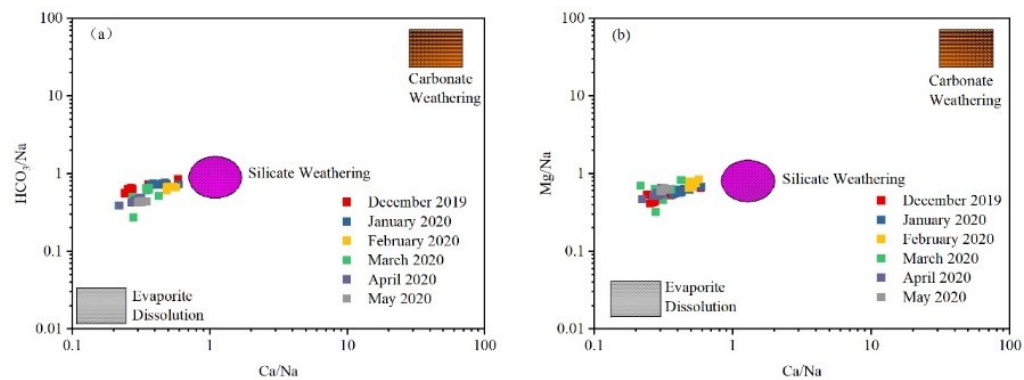

Fig. 5: The normalized diagram a) $\mathrm{Mg}^{2+} / \mathrm{Na}^{+}$vs $\mathrm{Ca}^{2+} / \mathrm{Na}^{+}$; b) $\mathrm{HCO}_{3}{ }^{-} / \mathrm{Na}^{+} \mathrm{vs} \mathrm{Ca}^{2+} / \mathrm{Na}^{+}$in the Xinbian River throughout the sampling period from December 2019 to May 2020.

\section{Correlation Analysis}

Correlation analysis is useful for determining the degree of connection between two or more ions in water and determining statistical significance (Jehan et al. 2019). Therefore, using correlation analysis is helpful to further establish the hydrochemical formation processes and ion sources for the Xinbian River. The correlation analysis results for the main conventional ions in the Xinbian River are shown in Fig. 6. It is generally considered that a correlation coefficient less than 0.5 indicates a weak correlation, while correlation coefficients between 0.5 and 0.75 indicate a moderate correlation, and correlation coefficients greater than 0.75 indicate a strong correlation.

It can be seen from Fig. 6 that EC, TDS, F, Cl, and $\mathrm{SO}_{4}{ }^{2-}$ were strongly correlated with each other, indicating that these water quality parameters may be associated with the same source. Only a weak negative correlation was observed between $\mathrm{pH}, \mathrm{Ca}^{2+}$, and $\mathrm{HCO}_{3}^{-}$. There was a moderate correlation between EC, TDS, and most of the conventional water ions, indicating that these water ions contributed to both EC and TDS to some degree. The correlation coefficients of $\mathrm{Ca}^{2+}$ with $\mathrm{Mg}^{2+}$ and $\mathrm{K}^{+}$were 0.43 and 0.56 , respectively, which indicates that cation exchange affected the conventional ions in Xinbian River water (Guan et al. 2018). The correlation coefficients for $\mathrm{F}^{-}$with $\mathrm{Cl}^{-}$and $\mathrm{SO}_{4}{ }^{2-}$ were 0.86 and 0.88 , respectively, with these strong correlations indicating that $\mathrm{F}^{-}$, $\mathrm{Cl}^{-}$and $\mathrm{SO}_{4}{ }^{2-}$ may have a common source. Combined with the results shown in Fig. 2, these findings indicate that the content of $\mathrm{F}^{-}$exhibited an increasing trend, exceeding the standard limit for $\mathrm{F}^{-}$according to the surface water quality standard (1 mg. $\left.\mathrm{L}^{-1}\right)$ in April and May 2020. Generally, there was a good degree of correlation observed between $\mathrm{Cl}^{-}$and $\mathrm{SO}_{4}{ }^{2-}$ in surface waters and their concentrations were high, indicating that $\mathrm{Cl}^{-}$and $\mathrm{SO}_{4}{ }^{2-}$ came from human activities such as agricultural non-point source pollution, domestic sewage, and industrial wastewater discharge.

\section{Principal Component Analysis}

The principal component analysis is a dimensionality reduction analytic method that divides a large number of variables 
into small, identifiable groups, allowing for the use of fewer variables to describe groupings of data (Singh et al. 2014). Therefore, principal component analysis is widely used in geochemical data sets ( $\mathrm{Li}$ et al. 2018, Yu et al. 2020a). The water quality parameters of 54 water samples collected in the Xinbian River from December 2019 to May 2020 were analyzed by principal component analysis and the results are shown in Fig. 6. The first principal component (PC1) accounted for $60.5 \%$ of the total variation, while the second principal component (PC2) accounted for $18.1 \%$ of the total variation, resulting in a cumulative contribution of $78.6 \%$. Therefore, the hydrogeochemical information of the Xinbian River can be generally reflected through principal component 1 and principal component 2 . It can be seen from Fig. 7 that $\mathrm{TDS}, \mathrm{F}^{-}, \mathrm{Cl}^{-}, \mathrm{SO}_{4}{ }^{2-}, \mathrm{Na}^{+}, \mathrm{K}^{+}$, and $\mathrm{Mg}^{2+}$ had relatively high positive loads in $\mathrm{PC} 1$; therefore, $\mathrm{PC} 1$ can be classified as being related to human activities. In contrast, PC2 was dominated by positive loads of $\mathrm{Ca}^{2+}, \mathrm{K}^{+}$, and $\mathrm{HCO}_{3}{ }^{-}$, with a negative load from $\mathrm{pH}$, indicating that $\mathrm{PC} 2$ may be related to rock weathering, e.g. natural activities.

As shown in Fig. 7, the 54 samples from the Xinbian River from December 2019 to May 2020 are scattered across all four quadrants. Among them, the water samples in December 2019 and March 2020 were mainly located in the third quadrant, the water samples in January 2020 and February 2020 were located in the second quadrant and the first quadrant, respectively, and water samples in April and May
2020 were mainly located in the fourth quadrant. The water quality indicators $\mathrm{SO}_{4}{ }^{2-}, \mathrm{Cl}^{-}$, and $\mathrm{F}^{-}$, related to agricultural non-point source pollution, exhibited a higher contribution to the fourth quadrant, which indicates that agricultural nonpoint source pollution gradually began to adversely affect water quality in April and May 2020.

\section{Irrigation Water Quality Evaluation}

Suzhou is located in the Huanghuai plain, which is an important grain-growing region in China. Owing to the developed water system in the study area, river water is mostly used to irrigate crops. An excess of dissolved ions in irrigation water affects the soil structure, reducing the production capacity of the soil and affecting the quality of agricultural products. Therefore, it is necessary to evaluate the quality of irrigation water taken from the Xinbian River. The irrigation water quality of the Xinbian River from December 2019 to May 2020 was calculated using Eq. (1)-(7), with the results given in Table 2.

SAR is an important parameter for the evaluation of irrigation water quality. Incorporating the concentrations of $\mathrm{Na}^{+}, \mathrm{Ca}^{2+}$, and $\mathrm{Mg}^{2+}$ with Eq. 2 (Lin et al. 2016), can reflect the degree to which $\mathrm{Na}^{+}$replaces $\mathrm{Ca}^{2+}$ and $\mathrm{Mg}^{2+}$ in the soil (Jiang et al. 2020). According to the SAR val2 ue, irrigation water can be divided into three categories: suitable for irrigation $(\mathrm{SAR}<18)$; unsuitable for irrigation $(18<$ SAR $<26)$; unsuitable for irrigation and harmful to

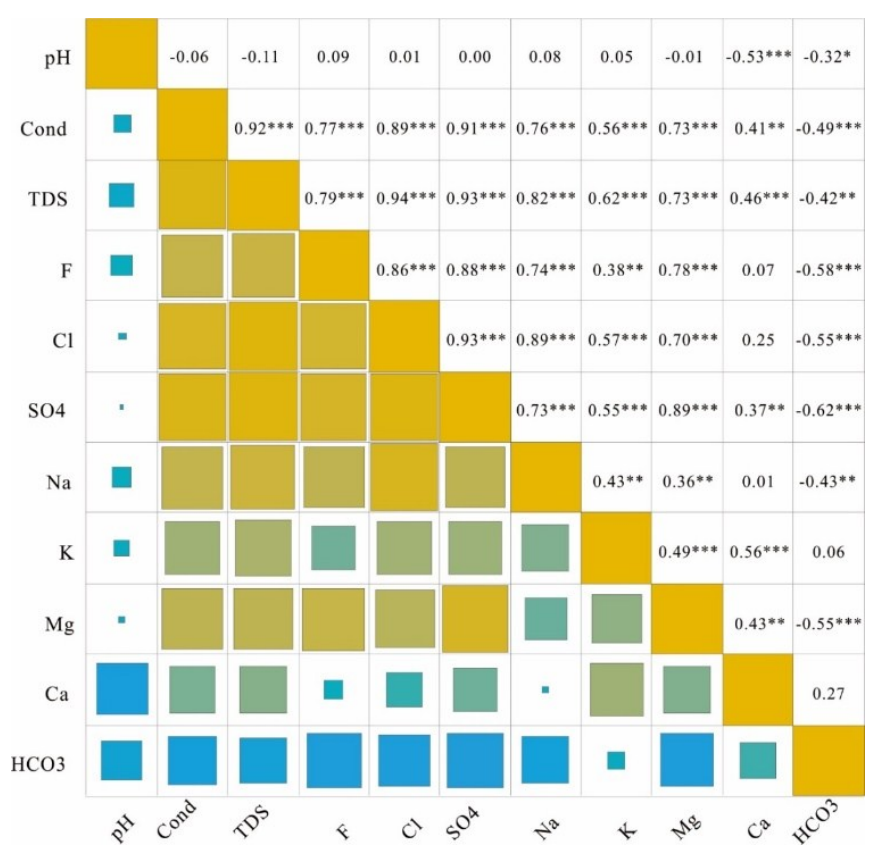

Fig. 6: Correlation analysis of hydrochemical parameters for the Xinbian River from December 2019 to May 2020. 
Table 2: Irrigation water quality indices.

\begin{tabular}{|llllllll|}
\hline Index & Minimum & Maximum & Mean & SD & Permissible limit & Unsuitable samples & Suitable samples [\%] \\
\hline SAR & 2.90 & 6.27 & 3.82 & 0.65 & $\leq 18$ & 0 & 100 \\
Na\% & 42.65 & 63.21 & 52.22 & 4.70 & $\leq 60$ & 3 & 94.44 \\
RSC & -4.57 & -0.21 & -2.66 & 1.17 & $\leq 2.5$ & 0 & 100 \\
MH & 52.71 & 76.32 & 62.46 & 4.67 & $\leq 50$ & 54 & 0 \\
PI & 54.14 & 76.31 & 64.94 & 5.09 & $\geq 25$ & 0 & 100 \\
KR & 0.71 & 1.68 & 1.07 & 0.21 & $\leq 1.0$ & 39 & 27.78 \\
PS & 5.69 & 11.28 & 7.70 & 1.35 & $\leq 10$ & 1 & 98.20 \\
\hline
\end{tabular}

crops $(26<$ SAR). As shown in Table 2 , the SAR values of all water samples in this study were less than 18, indicating that the water $\mathrm{Na}^{+}$hazard of Xinbian River water was within the safety limit.

EC is an important indicator of salinity and irrigation water with high EC content can easily lead to soil salinization. According to the EC value, irrigation water can be classified as $\mathrm{C} 1$, indicating low salinization $\left(\mathrm{EC}<250 \mu \mathrm{S} . \mathrm{cm}^{-1}\right)$; $\mathrm{C} 2$, indicating medium salinization $\left(250-750 \mu{\left.\mathrm{S} . \mathrm{cm}^{-1}\right)}^{-1} \mathrm{C} 3\right.$, indicating high salinization $\left(750-2250 \mu \mathrm{S}_{\mathrm{cm}}{ }^{-1}\right)$; or C4, indicating high salinization $\left(>2250 \mu \mathrm{S} . \mathrm{cm}^{-1}\right)$. The effects of SAR and EC values on soil are integrated into the USSL diagram (Yu et al. 2020b) (Fig. 8a), showing that 52 of the water samples (96.30\%) fell in the C3S1 area, indicating high salinity. If the soil leaching conditions are good, water samples in the C3S1 area can be used for irrigation, otherwise, they should only be used for irrigating plants with strong salt tolerance.

$\mathrm{Na} \%$ is an important indicator of sodium harm, as higher $\mathrm{Na} \%$ values may affect the structure of the soil, reduce soil permeability, harden soil, and reduce gas exchange between the soil and the atmosphere. In this study, the $\mathrm{Na} \%$ value of the Xinbian River ranged between 2.90 and 6.27, exhibiting an average of 3.82 , with only three water samples exceeding the standard limit.

Wilcox diagram analysis was used to show the effects of $\mathrm{Na} \%$ and EC on soil and crops. According to the Wilcox diagram (Fig. 8b), 36 water samples $(66.67 \%)$ were in the good allowable region, while 18 water samples were in the suspicious region.

RSC is an important parameter to evaluate the quality of irrigation water (Ghobadi et al. 2020), comprehensively characterizing the relationship between $\mathrm{HCO}_{3}{ }^{-}+\mathrm{CO}_{3}{ }^{2-}$ and $\mathrm{Ca}^{2+}+\mathrm{Mg}^{2+}$. Large amounts of calcium and magnesium ions can reduce soil permeability, while high RSC values in irrigation water indicate an increase in the content of sodium in the soil. Therefore, if the RSC value is greater than 2.5 meq. $\mathrm{L}^{-1}$, the water is not suitable for use for irrigation. As shown in
Table 2, the RSC values of all water samples were less than 2.5 meq. $\mathrm{L}^{-1}$ and therefore, were below the standard limit.

$\mathrm{MH}$ is another important index to evaluate irrigation water quality, mainly reflecting the proportional relationship between $\mathrm{Mg}^{2+}$ and $\mathrm{Ca}^{2+}+\mathrm{Mg}^{2+}$. When the proportion of $\mathrm{Mg}^{2+}$ is large, it will cause the dispersion of soil clay particles, changing the soil structure and reducing crop yields. If the MH value is less than 50, the water is suitable for irrigation. As shown in Table 2, the MH value of Xinbian River water ranged between 52.71-76.32 (average 62.46), indicating that corresponding measures should be taken to reduce the proportion of $\mathrm{Mg}^{2+}$ in irrigation water.

In addition, the permeability index (PI) is also a key parameter to evaluate the quality of irrigation water (Sehlaoui et al. 2020) and it can be seen from Table 2 that the PI values of all water samples were within the limit. The KR parameter proposed by Keelly can be used to evaluate the quality of irrigation water. As shown in Table 2, the KR value of Xinbian River water ranged between 0.71 and 1.68 (average 1.07), with the KR value of 39 water samples exceeding the limit value $(<1)$.

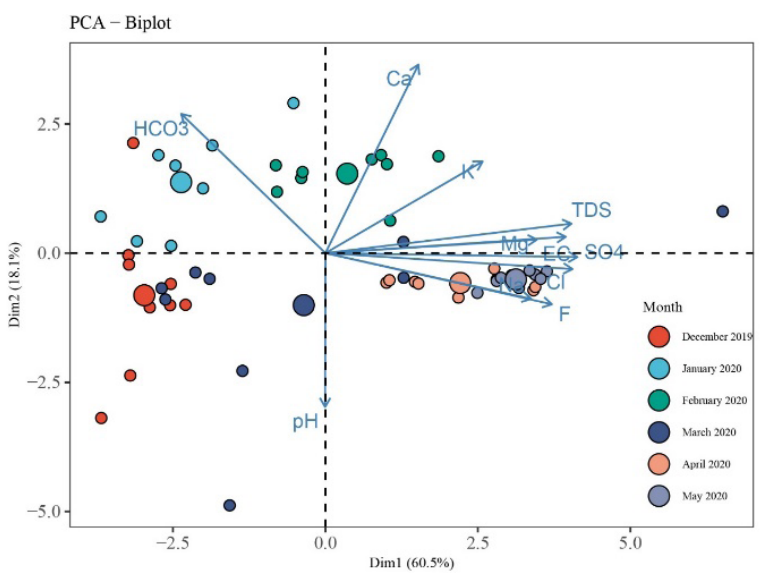

Fig. 7: The Principal component analysis loading plot for hydrochemical parameters in the Xinbian River from December 2019 to May 2020. 

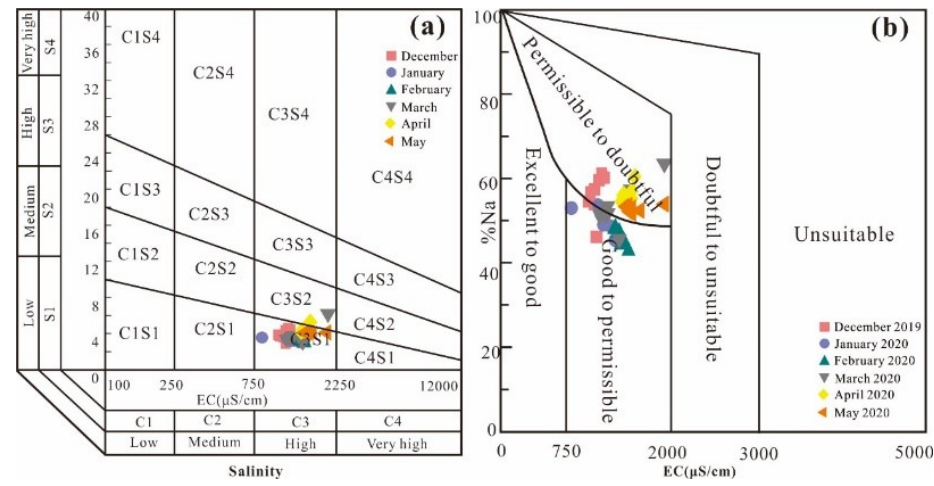

Fig. 8: USSL diagram (a) and Wilcox diagram (b) for the Xinbian River from December 2019 to May 2020.

\section{CONCLUSION}

(1) From December 2019 to May 2020, the concentrations of $\mathrm{Cl}^{-}, \mathrm{EC}, \mathrm{F}^{-}, \mathrm{Mg}^{2+}, \mathrm{Na}^{+}, \mathrm{SO}_{4}{ }^{2-}$, and TDS in the Xinbian River increased, with indicators related to agricultural non-point source pollution $\left(\mathrm{SO}_{4}{ }^{2-}\right.$ and $\left.\mathrm{F}^{-}\right)$exceeding the standard limits in May 2020, according to China's surface water quality standard. There were three hydrochemical characteristic types identified in the Xinbian River: $\mathrm{Na}-\mathrm{HCO}_{3}{ }^{-}, \mathrm{Na}-\mathrm{Cl}$, and $\mathrm{Na}-\mathrm{SO}_{4}$, with $\mathrm{Na}-\mathrm{SO}_{4}$ being the dominant hydrochemical type $(77.77 \%)$.

(2) Gibbs diagram analysis showed that from December 2019 to May 2020, Xinbian River water was mainly affected by rock weathering, while a few water samples indicated an effect from rocks, indicating that the ions in Xinbian River water mainly originated from rock weathering, while agricultural non-point source pollution also exerted a certain impact on the ion composition of the Xinbian River.

(3) The findings of the correlation study for the primary water quality metrics revealed a relationship between EC and TDS and the majority of water quality indicators. Furthermore, $\mathrm{SO}_{4}{ }^{2-}, \mathrm{Cl}^{-}$, and $\mathrm{F}^{-}$exhibited a good positive correlation with each other, indicating that $\mathrm{SO}_{4}{ }^{2-}, \mathrm{Cl}^{-}$, and $\mathrm{F}^{-}$may originate from the same source. The results of the principal component analysis showed that the intensity of interference from agricultural non-point source pollution on Xinbian River water increased from December 2019 to May 2020.

(4) The overall water quality of irrigation water from the Xinbian River was good and most of the irrigation water index evaluation results were good. The calculation results for the indices SAR, RSC, and PI show that from December 2019 to May 2020, Xinbian River water was consistently suitable for use as irrigation water.
However, the potential for magnesium damage should be monitored and mitigated by regulating the release of $\mathrm{Ca}^{2+}$.

\section{ACKNOWLEDGMENTS}

This research was supported by Anhui Provincial Natural Science Foundation of China (2008085MD122), Zhejiang Provincial Natural Science Foundation of China under Grant No. LQ20D010009, Key Program for Outstanding Young Talents in Higher Education Institutions of Anhui Province (gxyqZD2021134), Research development foundation of Suzhou University (2021fzjj28), Doctoral Scientific Research Foundation of Suzhou University (2019jb15), and Demonstration Teaching Organization of Anhui Education Department (416), and Dual-ability Teaching Team Project of Suzhou University (2020XJSN06).

\section{REFERENCES}

Bob, M., Abd Rahman, N., Elamin, A. and Taher, S. 2016. Assessment of groundwater suitability for irrigation in Madinah City, Saudi Arabia. Arab. J. Geosci., 9: 38.

Chen, K., Sun, L., Liu, Q., Cao, W. and Tang, J. 2019. Quality evaluation and its controlling factor analyses of shallow groundwater in the urban area of Suzhou, Anhui province, China. Fresenius Environ. Bull., 28(9): 6801-6807.

Chen, K., Sun, L.L. and Tang, J. 2020. Hydrochemical differences between river water and groundwater in Suzhou, Northern Anhui Province, China. Open Geosci., 12(1): 1421-1429.

Gaillardet, J., Dupre, B., Louvat, P. and Allegre, J.C. 1999. Global silicate weathering and $\mathrm{CO}_{2}$ consumption rates are deduced from the chemistry of large rivers. Chem. Geol., 159(1-4): 3-30.

Ghobadi, A., Cheraghi, M., Sobhanardakani, S., Lorestani, B. and Merrikhpour, H. 2020. Hydrogeochemical characteristics, temporal, and spatial variations for evaluation of groundwater quality of Hamedan-Bahar Plain as a major agricultural region, West of Iran. Environ. Earth. Sci., 79: 428.

Guan, L.S., Gui, H.R., Kang, Z.Y., Zhao, H.H and Li, J. 2018. Hydrochemical characteristics and water quality assessment in goaf water of Kouquangou mining area in Datong, Shanxi, China. Fresenius Environ. Bull., 27(12A): 9315-9324. 
Hu, J., Long, Y., Zhou, W., Zhu, C., Yang, Q., Zhou, S. and Wu, P. 2020. Influence of different land-use types on hydrochemistry and heavy metals in surface water in the lakeshore zone of the Caohai wetland, China. Environ. Pollut., 267: 115454.

Jiang, Y., Gui, H., Yu, H., Wang, M., Fang, H., Wang, C., Chen, C., Zhang, Y. and Huang, Y. 2020. Hydrochemical characteristics and water quality evaluation of rivers in different regions of cities: A case study of Suzhou City in Northern Anhui Province, China. Water, 12(4): 950.

Jehan, S., Khan, S., Khattak, S.A., Muhammad, S., Rashid, A. and Muhammad, N. 2019. Hydrochemical properties of drinking water and their sources apportionment of pollution in Bajaur agency, Pakistan. Measurement, 139: 249-257.

Li, J., Gui, H., Hu, R., Chen, L., Xia, Y., Fan, H., Yu, H. and Wang, M. 2020. Analysis of heavy metal sources and health risk assessment of typical coal mine collapsed lakes in Huaibei Coalfield, Anhui Province, China. Pol. J. Environ. Stud., 29(5): 3193-3202.

Li, Z., Li, Z., Song, L., Ma, J. and Song, Y. 2018. Environment significance and hydrochemical characteristics of supra-permafrost water in the source region of the Yangtze River. Sci. Total Environ., 644: 1141-1151.

Lin, M.L., Peng, W.H. and Gui, H.R. 2016. Hydrochemical characteristics and quality assessment of deep groundwater from the coal-bearing aquifer of the Linhuan coal-mining district, Northern Anhui Province, China. Environ. Monit. Assess., 11: 188: 202.

Sehlaoui, H., Hassikou, R., Moussadek, R., Zouahri, A., Douaik, A., Iiach, H., Ghanimi, A. and Dakak, H. 2020. Evaluation of water quality for agricultural suitability in the Benslimane region, Morocco. Environ. Monit. Assess., 17: 192: 587.

State Environmental Protection Administration (SEPA). 2002. Technical Specifications Requirements for Monitoring of Surface Water and Waste Water (HJ/T 91-2002). (in Chinese)

Singh, V.B., Ramanathan, A.L., Pottakkal, J.G. and Kumar, M. 2014. Sea- sonal variation of the solute and suspended sediment load in Gangotri glacier meltwater, central Himalaya, India. J. Asian Earth Sci., 79: 224-234.

Tang, J.F., Wang, W.D., Yang, L., Qiu, Q.L.L., Lin, M.X., Cao, C.L. and Li, X.H. 2020. Seasonal variation and ecological risk assessment of dissolved organic matter in a peri-urban critical zone observatory watershed. Sci. Total Environ., 707: 136093.

Valappil, N.K.M., Viswanathan, P.M. and Hamza, V. 2020. Seasonal hydrochemical dynamics of surface water in the Limbang River, Northern Borneo: Evaluating for spatial and temporal trends. Arab. J. Geosci., 13: 980.

Wang, M., Gui, H., Hu, R., Zhao, H., Li, J., Yu, H. and Fang, H. 2019a. Hydrogeochemical characteristics and water quality evaluation of carboniferous Taiyuan formation limestone water in Sulin mining area in Northern Anhui, China. Int. J. Environ. Res. Public Health, 16: 2512.

Wang, F., Zhao, Y., Chen, X. and Zhao, H. 2019b. Hydrochemistry and its controlling factors of rivers in the source region of the Nujiang River on the Tibetan Plateau. Water, 11: 2166.

Xia, Y.T., Gui, H.R., Zhao, H.H., Li, J. and Guan, L.S. 2019. Temporal variability of hydro-chemical characteristics and water quality assessment of collapse pond in Zhuxianzhuang coal mining area, China. Fresenius Environ. Bull., 28(1): 402-409.

Yu, H., Gui, H., Jiang, Y., Li, Z., Wang, M., Fang, H., Wang, C., Chen, C., Qiu, H. and Zhang, Y. 2020a. Characteristics of dissolved organic matter content in urban rivers under different environmental impact zones: A case study of China's Tuo River. Pol. J. Environ. Stud., 29(5): 3891-3900.

Yu, H., Gui, H., Zhao, H., Wang, M., Li, J., Fang, H., Jiang, Y. and Zhang, Y. 2020b. Hydrochemical characteristics and water quality evaluation of shallow groundwater in Suxian mining area, Huaibei coalfield, China. Int. J. Coal Sci.Technol., 7: 825-835. 